\title{
Rancang Bangun Sistem Informasi Penitipan Motor Berbasis Web Dengan Menggunakan PHP Dan MYSQL Di Terminal Purwokerto
}

\author{
Elisa Usada $^{1}$, Yana Yuniarsyah ${ }^{2}$, Dwi Mai Choiriah ${ }^{3}$ \\ Program Studi Diploma III TeknikTelekomunikasi, Purwokerto \\ 1,2,3 Akademi Teknik Telekomunikasi Sandhy Putra Purwokerto \\ 1elisa@akatelsp.ac.id, ${ }^{2}$ sawahlega@yahoo.com, ${ }^{3}$ D309017@yahoo.com
}

\begin{abstract}
ABSTRAK
Penitipan kendaraan Terminal Purwokerto menggunakan cara administrasi manual. Program sstem informasi penitipan motor ini dibuat dalam rangka usaha komputerisasi data perparkiran di Terminal Purwokerto. Perancangan sistem informasi penitipan ini metode yang digunakan yaitu menggunakan metode waterfall. Pembuatan sistem informasi penitipan ini menghasilkan 3 user leveling yaitu operator, atasan dan pengguna parkir. Tabel yang dihasilkan sebanyak 3 tabel. Program sistem informasi penitipan ini menggunakan penyimpanan MySQL sebagai database server karena mampu menerima dan mengirimkan data dengan cepat serta dapat menyimpan data penitipan dalam jumlah yang banyak. Pengujian program sistem informasi penitipan ini dimulai dari tahap pengujian sistem, pengujian interface, proses upload ke web hosting dan melakukan pengujian jaringan. Diharapkan sistem informasi penitipan ini dapat dikembangkan dalam segi keamanan dan kelengkapan datanya, tambahan fasilitas backup database dan lebih bagus lagi jika ada penambahan RFID dalam proses output dan input data parkir di penitipan.
\end{abstract}

Kata Kunci: Sistem Informasi Penitipan motor, PHP, MySQL, Database dan Waterfall.

\section{PENDAHULUAN}

\subsection{Latar Belakang}

Proses penyimpanan dan pengolahan data pembayaran parkir di Terminal Purwokerto dilakukan secara manual. Petugas mencari buku administrasi data parkir satupersatu. Buku administrasi parkir tersebut dapat hilang atau terselip sehingga petugas memerlukan waktu untuk mencari. Rekap data untuk pelaporan tiap bulan ke atasan juga masih dilakukan secara manual dengan bentuk buku catatan.

Untuk menunjang kemajuan sistem informasi pada pengolahan data administrasi di tempat penitipan kendaraan Terminal Purwokerto, maka penulis mengangkat judul mengenai "RANCANG BANGUN SISTEM INFORMASI PENITIPAN MOTOR
BERBASIS WEB DENGAN MENGGUNAKAN PHP DAN MYSQL DI TERMINAL PURWOKERTO”.

Penulis harapkan dengan adanya sistem ini dapat membantu bagian administrasi penitipan dalam mengelola administrasi pembayaran penitipan dan mendata kendaraan yang input dan output dari tempat penitipan, menjadi lebih mudah. Sehingga dapat meningkatkan pelayanan informasi mengenai administrasi pembayaran dan penyimpanan data penitipan dengan tepat, cepat dan akurat. Dan juga pada sistem informasi penitipan ini menggunakan jaringan internet untuk mempermudah atasan mengakses data parkir atau laporan tiap bulannya, serta dapat memberikan informasi kepada pengguna parkir. 


\section{METODOLOGI PENELITIAN}

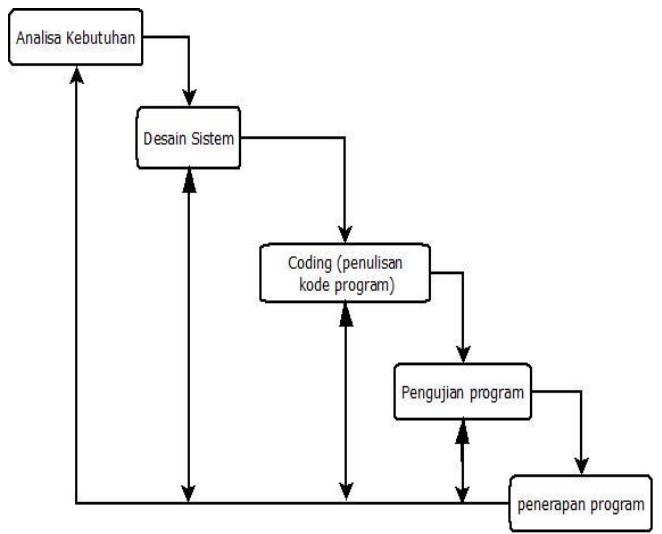

Gambar 8. Model pengembangan perangkat lunak waterfall

\subsection{Analisa Kebutuhan}

Analisa kebutuhan ini merupakan Kebutuhan yang diperlukan dalam pembuatan sistem informasi penitipan ini yaitu:

1. Instrumen Penelitian

Fasilitas instrumen penelitian yaitu fasilitas software dan hardware.

a. Software

1) XАMPP versi win32-1.6.3a, program ini mempunyai satu paket web server Apache, PHP dan MySQL.

2) Dreamweaver CS5 sebagai teks editor untuk desain dan penulisan script PHP.

3) Web browser yang digunakan Mozila firefox, yang berguna untuk menampilkan interface program yang telah dibuat.

b. Hardware yang digunakan dalam pembuatan program ini yaitu:
1) Laptop dual core processor T4200

2) Procesor $2 \mathrm{GHz}$

3) Random Access Memori (RAM) 2 GB

\section{4) Hardisk $250 \mathrm{~GB}$}

2. Metode Pengumpulan data

a. Observasi

Penulis melakukan survey langsung ke lokasi penelitian untuk mengamati prosedur sistem pendataan kendaraan yang parkir serta pembayarannya. Pada tempat penelitian yaitu di Terminal Purwokerto masih dilakukan secara manual. Dan penulis hanya mengambil beberapa sampel data-data yang diperlukan.

b. Wawancara

Penulis juga melakukan wawancara kepada pihak pengelola penitipan Terminal Purwokerto dan petugas yang berjaga.

\subsection{Desain}

Proses desain ini penulis melakukan desain dengan dibantu aplikasi Dreamweaver CS5 sebagai teks editor.

\subsection{Coding dan Testing}

Pembuatan sistem informasi penitipan ini penulis menggunakan 
bahasa pemrograman PHP, setelah pengkodean selesai maka dilakukan testing terhadap sistem ini.

\subsection{Penerapan}

Tahapan ini setelah melakukan tahapan diatas maka akan diterapkan di Terminal Purwokerto.

\subsection{Pemeliharaan}

Pemeliharaan dilakukan setelah sistem ini diterapkan, pemeliharaan dilakukan karena perangkat lunak yang sudah disampaikan kepada pelanggan pasti akan mengalami perubahan.

\section{PERANCANGAN DAN PEMBUATAN PROGRAM}

\subsection{Persiapan Perangkat Lunak (Software)}

Persiapan software yang digunakan penulis untuk perancangan sistem informasi penitipan adalah melakukan instalasi pada XAMPP win32-1.6.3a dan Dreamweaver CS5.

\subsection{Perancangan (Desain)}

\section{a. DFD (Data Flow Diagram)}

\section{DFD (Data Flow Diagram)}

adalah alat bantu yang memudahkan dalam pemodelan dan penggambaran suatu sistem yang ada dan akan dibuat yang dihubungkan satu sama lain dengan alur data. Diagram konteks adalah terdiri dari proses dan menggambarkan hubungan terminator dengan sistem yang mewakili suatu proses. DFD konteks menggambarkan secara global hubungan antar entitas dan penyimpanan datanya. DFD konteks dari Sistem Informasi Penitipan di Terminal Purwokerto, yaitu sebagai berikut:

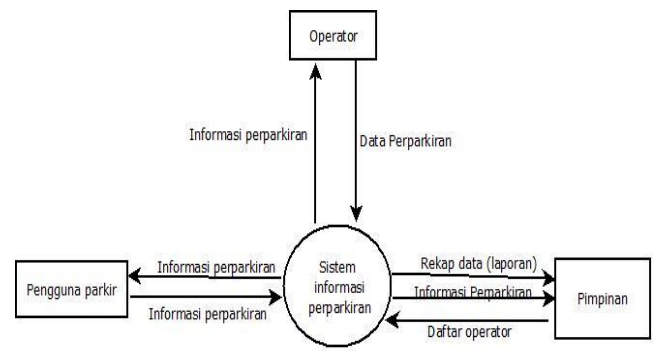

Gambar 9. DFD Level 0

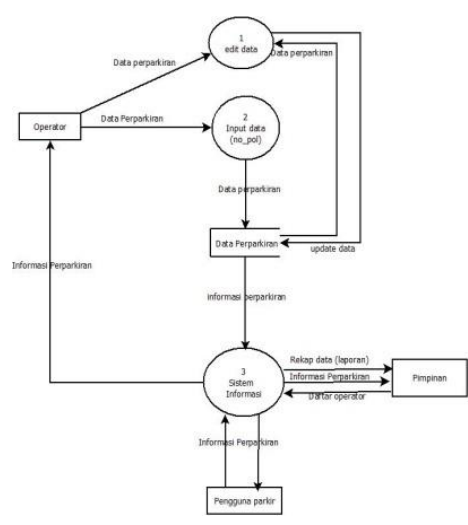

Gambar 10.DFD Level 1

\section{b. User Leveling}

User leveling ini terbagi menjadi tiga tingkatan yaitu:

\section{1) Operator}

User sebagai operator yaitu melakukan input data no polisi kendaraan yang dititipkan, menghapus data, edit data serta melakukan transaksi pembayaran dengan pengguna parkir. 
2) Atasan

User sebagai pimpinan yaitu dapat melihat informasi tentang sisa tempat penitipan yang kosong, mempunyai ijin melakukan pendaftaran, edit username dan password baru untuk operator dan melihat laporan data perbulannya.

\section{3) Pengguna Parkir (Umum)}

User sebagai pengguna parkir (umum) yaitu hanya diperbolehkan melihat tentang penitipan sisa tempat penitipan yang kosong dan melihat berapa biaya yang harus ditanggung selama pengguna menitipkan kendaraannya.

\section{c. Diagram E-R (Entity- \\ Relationship)}

Model E-R adalah suatu model yang digunakan untuk menggambarkan data dalam bentuk entitas, atribut dan hubungan antar entitas. Diagram E-R untuk Sistem Informasi Penitipan di Terminal Purwokerto, yaitu:

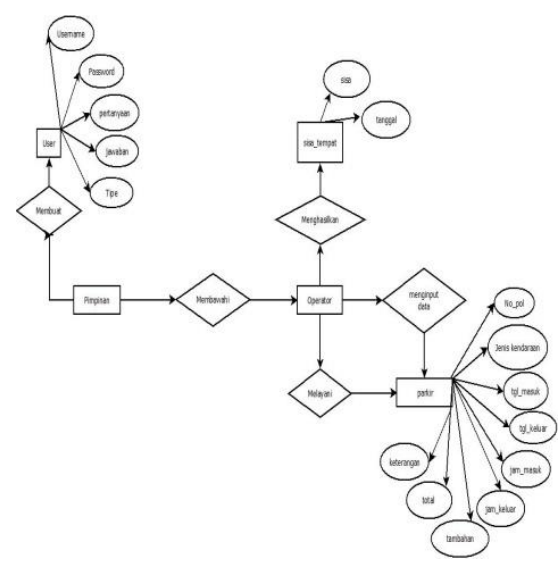

Gambar 11. Diagram E-R untuk Sistem Informasi Penitipan

\section{d. Pembuatan Database}

a.) Tabel parkir

Tabel parkir ini digunakan untuk menampung penyimpanan data jika ada pengguna parkir yang ingin menitipkan sepeda motornya. Primary key: no_pol

Tabel 1. parkir

\begin{tabular}{|c|c|c|}
\hline Nama field & Type & Keterangan \\
\hline no_pol & $\begin{array}{l}\text { Varchar } \\
\text { (10) }\end{array}$ & $\begin{array}{l}\text { Primary key, no } \\
\text { polisi yang } \\
\text { diinput. }\end{array}$ \\
\hline tgl_masuk & Date & $\begin{array}{c}\text { Tanggal masuk } \\
\text { sepeda motor }\end{array}$ \\
\hline tgl_keluar & Date & $\begin{array}{c}\text { Tanggal keluar } \\
\text { sepeda motor }\end{array}$ \\
\hline jenis & $\begin{array}{l}\text { Varchar } \\
\text { (25) }\end{array}$ & $\begin{array}{c}\text { Diisi dengan jenis } \\
\text { kendaraan yang } \\
\text { masuk }\end{array}$ \\
\hline jam_masuk & Time & $\begin{array}{c}\text { Terisi otomatis } \\
\text { saat sepeda motor } \\
\text { masuk }\end{array}$ \\
\hline jam_keluar & Time & $\begin{array}{c}\text { Terisi otomatis } \\
\text { saat sepeda motor } \\
\text { keluar }\end{array}$ \\
\hline tambahan & $\begin{array}{c}\text { Varchar } \\
(100)\end{array}$ & $\begin{array}{c}\text { Diisi dengan } \\
\text { tambahan yang } \\
\text { dititipkan }\end{array}$ \\
\hline total & Int (11) & $\begin{array}{c}\text { Otomatis } \\
\text { menampilkan total } \\
\text { biaya penitipan }\end{array}$ \\
\hline keterangan & $\begin{array}{c}\text { Varchar } \\
(100)\end{array}$ & $\begin{array}{c}\text { Diisi untuk } \\
\text { pemberian } \\
\text { informasi sisa } \\
\text { tempat parkir yang } \\
\text { kosong }\end{array}$ \\
\hline
\end{tabular}

b.) Tabel sisa_tempat

Tabel sisa_tempat ini untuk menampung pengolahan informasi tentang sisa tempat penitipan yang di operasikan oleh operator. Primary key: Sisa.

Tabel 2. sisa_tempat

\begin{tabular}{|c|c|c|}
\hline $\begin{array}{c}\text { Nama } \\
\text { field }\end{array}$ & Type & Keterangan \\
\hline Sisa & $\begin{array}{c}\text { Varchar } \\
(100)\end{array}$ & $\begin{array}{c}\text { Primary key, } \\
\text { Diisi dengan } \\
\text { pemberitahuan } \\
\text { sisa tempat } \\
\text { penitipan. }\end{array}$ \\
\hline tanggal & Date & $\begin{array}{c}\text { Terisi } \\
\text { otomatis }\end{array}$ \\
\hline
\end{tabular}




\section{c.) Tabel user}

Tabel user ini digunakan untuk menampung penggunaan dalam menu login, jadi user yang belum terdaftar tidak dapat menggunakan aplikasi pengolahan nilai. Primary

Key: username.

Tabel 3. user

\begin{tabular}{|c|c|c|}
\hline $\begin{array}{c}\text { Nama } \\
\text { field }\end{array}$ & Type & Keterangan \\
\hline username & $\begin{array}{c}\text { Varchar } \\
(30)\end{array}$ & $\begin{array}{c}\text { Primary key, } \\
\text { Auto } \\
\text { Increament, } \\
\text { nama user }\end{array}$ \\
\hline password & $\begin{array}{c}\text { Varchar } \\
(32)\end{array}$ & $\begin{array}{c}\text { Password } \\
\text { user }\end{array}$ \\
\hline pertanyaan & $\begin{array}{c}\text { Varchar } \\
(50)\end{array}$ & $\begin{array}{c}\text { Berisi } \\
\text { pertanyaan } \\
\text { yang dipilih } \\
\text { operator pada } \\
\text { saat ingin } \\
\text { mendaftarkan } \\
\text { username }\end{array}$ \\
\hline jawaban & $\begin{array}{c}\text { Varchar } \\
(50)\end{array}$ & $\begin{array}{c}\text { Berisi } \\
\text { jawaban dari } \\
\text { pertanyaan }\end{array}$ \\
\hline tipe & text & Tipe user \\
\hline
\end{tabular}

\section{e. Struktur Program}

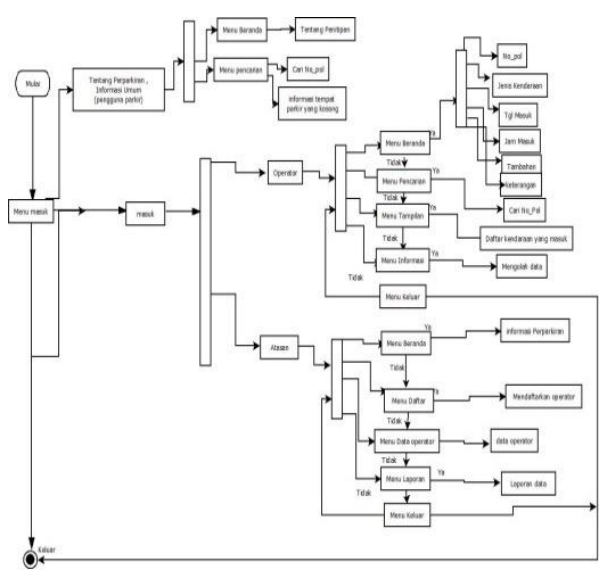

Gambar 12. Struktur Program

\section{f. Tampilan Sistem Informasi}

\section{Penitipan}

Pembuatan desain untuk tampilan web sistem informasi penitipan ini, penulis menggunakan Dreamweaver CS5, yang memudahkan dalam pembuatan desain sekaligus pengkodean.

Layout dari sistem informasi penitipan ini menggunakan files yang disimpan menggunakan ekstensi .php, karena didalamnya terdapat scripts php. Layout terbagi tiga bagian yaitu Header, isi dan Footer. Untuk layout Beranda operator, pimpinan, dan Beranda untuk informasi umum (pengguna parkir) sedikit berbeda.

\section{g. Desain Jaringan}

Cara kerja jaringan internet yaitu protocol TCP/IP memungkinkan semua komputer dapat berkomunikasi satu dengan lainnya. Pada saat browser meminta data atau informasi ke server maka instruksi permintaan data oleh browser tersebut dikemas didalam TCP yang merupakan protocol berikutnya yaitu HTTP. HTTP ini yang merupakan protocol yang digunakan dalam world wide web (www) antar komputer yang terhubung dalam jaringan didunia. Data yang di passing dari browser ke server disebut HTTP request, dan kemudian web server akan 
mencari data HTML yang ada dan dikemas dalam TCP protocol dan dikirim kembali ke browser. Gambar 3.21 merupakan gambar jaringan pada penitipan.

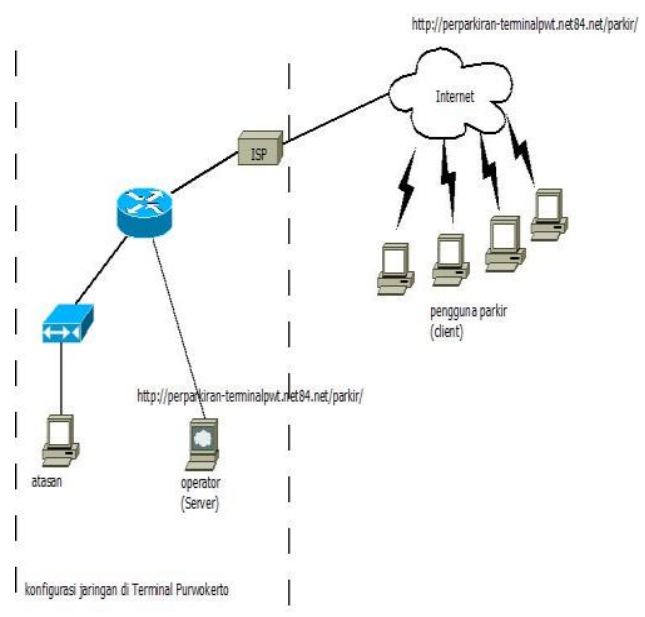

Gambar 13. Jaringan Pada penitipan

\section{PENGUJIAN PROGRAM}

\subsection{Pengujian Sistem}

Pengujian sistem disebut juga pengujian validasi. Jenis pengujian yang digunakan untuk validasi menggunakan jenis pengujian Black-Box Testing, pengujian ini dimaksudkan untuk mengetahui apakah fungsi-fungsi, masukan dan keluaran dari perangkat lunak sesuai dengan spesifikasi yang dibutuhkan. Pengujian ini, perangkat lunak diuji untuk persyaratan fungsionalitas yang dilakukan dalam bentuk tertulis untuk memeriksa apakah aplikasi dapat berjalan dengan apa yang diharapkan sebelumnya. Pengujian yang dilakukan yaitu berfungsi atau berjalannya proses untuk setiap menu yang telah ada.
Tabel 4. Pengujian Sistem Informasi Penitipan

\begin{tabular}{|c|c|c|c|c|}
\hline \multirow[t]{2}{*}{ No } & \multirow{2}{*}{$\begin{array}{c}\text { Menu } \\
\text { yang } \\
\text { Diujikan }\end{array}$} & \multirow[t]{2}{*}{ Proses } & \multicolumn{2}{|c|}{ Hasil } \\
\hline & & & Berhasil & Gagal \\
\hline 1 & $\begin{array}{l}\text { Menu } \\
\text { masuk }\end{array}$ & $\begin{array}{l}\text { Dengan } \\
\text { memasukan } \\
\text { username, } \\
\text { password } \\
\text { dan tipe } \\
\text { yang benar }\end{array}$ & $\sqrt{ }$ & \\
\hline 2 & $\begin{array}{l}\text { Lupa } \\
\text { password }\end{array}$ & $\begin{array}{l}\text { Simpan } \\
\text { data,menam } \\
\text { pilkan } \\
\text { password } \\
\text { yang lupa }\end{array}$ & $\sqrt{ }$ & \\
\hline 3 & $\begin{array}{l}\text { Data } \\
\text { Pengguna } \\
\text { parkir } \\
\text { (no_pol) }\end{array}$ & $\begin{array}{l}\text { Simpan data } \\
\text { (input, } \\
\text { update, } \\
\text { hapus) }\end{array}$ & $\sqrt{ }$ & \\
\hline 4 & $\begin{array}{l}\text { Pencarian } \\
\text { no_pol }\end{array}$ & Output biaya & $\sqrt{ }$ & \\
\hline 5 & $\begin{array}{l}\text { Informasi } \\
\text { sisa } \\
\text { tempat } \\
\text { parkir }\end{array}$ & $\begin{array}{l}\text { Simpan } \\
\text { (input,updat } \\
e \text {, hapus) }\end{array}$ & $\sqrt{ }$ & \\
\hline 6 & $\begin{array}{l}\text { Daftar } \\
\text { operator }\end{array}$ & $\begin{array}{l}\text { Simpan } \\
\text { data(input) }\end{array}$ & $\sqrt{ }$ & \\
\hline 7 & $\begin{array}{l}\text { Data } \\
\text { operator }\end{array}$ & $\begin{array}{l}\text { Output data } \\
\text { operator, } \\
\text { edit, hapus }\end{array}$ & $\sqrt{ }$ & \\
\hline 8 & $\begin{array}{l}\text { Informasi } \\
\text { sisa } \\
\text { tempat } \\
\text { parkir }\end{array}$ & output & $\sqrt{ }$ & \\
\hline 9 & $\begin{array}{l}\text { Laporan } \\
\text { data }\end{array}$ & $\begin{array}{l}\text { Menampilka } \\
\mathrm{n} \text { rekap data } \\
\text { perbulan }\end{array}$ & $\sqrt{ }$ & \\
\hline 10 & $\begin{array}{l}\text { Data } \\
\text { penitipan }\end{array}$ & $\begin{array}{l}\text { Melihat } \\
\text { biaya parkir }\end{array}$ & $\sqrt{ }$ & \\
\hline
\end{tabular}

\subsection{Pengujian Interface Program}

Berikut adalah merupakan beberapa tampilan (interface) program dari "Sistem Informasi Penitipan di Terminal Purwokerto", yaitu:

1. Tampilan Halaman Utama

a. Halaman Masuk

Halaman Masuk adalah halaman yang digunakan untuk pengguna pertama kali memakai sistem aplikasi ini. Pengguna 
sistem dapat masuk ke dalam

sistem jika pengguna

memasukkan username, password dan tipe lalu memilih tombol masuk. Data yang dimasukkan akan dieksekusi oleh sistem dan akan masuk ke halaman sesuai dengan tipe atau level user.

b. Tampilan Halaman Lupa

Password

Halaman lupa password digunakan untuk pengguna yang ingin masuk ke dalam sistem dan pengguna lupa dengan passwordnya sendiri, maka pengguna dapat memilih tombol lupa password yang terletak di bawah tombol masuk. Saat pengguna memilih tombol lupa password maka akan tampil halaman lupa password, pengguna tinggal mengisikan username, pertanyaan, dan jawaban setelah itu memilih tombol kirim.

2. Tampilan Halaman Tentang

Penitipan

Halaman Tentang Penitipan adalah halaman untuk pengguna parkir yang sedang menitipkan kendaraannya ataupun yang belum pernah menitipkan kendaraanya. Halaman ini berguna untuk pengguna parkir yang sedang menitipkan kendaraannya serta pengguna umum, yang berisi informasi-informasi tempat parkir, seperti tentang penitipan kendaraan di Terminal Purwokerto, tentang informasi sisa tempat parkir yang kosong dan pengguna parkir dapat melihat biaya yang harus dibayar selama menitipkan kendaraannya.

a. Menu Beranda

Menu beranda ini merupakan menu awal ketika pengguna parkir memilih atau masuk ke tentang penitipan, berisi tentang penitipan di Terminal Purwokerto.

b. Menu Pencarian

Menu pencarian ini digunakan untuk melihat tentang informasi sisa tempat parkir yang kosong tiap harinya, dan di dalam menu ini pengguna parkir dapat melihat biaya yang harus dibayar selama pengguna, menitipkan kendaraannya. Dengan memasukan no polisi pengguna parkir maka akan muncul biaya yang di tanggung.

c. Menu Kembali

Menu kembali ini merupakan menu untuk kembali ke halaman utama, yaitu ke halaman masuk.

3. Tampilan Halaman untuk Operator Halaman operator adalah halaman yang digunakan untuk input data, mengolah data parkir. Halaman operator setelah memasukkan username, password, dan tipe untuk masuk akan tampil halaman untuk operator. Pada 
halaman operator disediakan menumenu yang meliputi menu beranda, menu pencarian, menu tampilan, menu informasi dan menu keluar.

a. Menu Beranda

$$
\text { Menu beranda ini }
$$

merupakan menu awal ketika operator masuk ke halaman operator. Pada menu beranda terdapat tabel untuk operator melakukan input data jika ada pengguna parkir yang ingin menitipkan kendaraannya terdiri dari No polisi (diisi dengan no polisi pengguna parkir), jenis kendaraan (diisi dengan jenis kendaraan yang dititipkan), Tanggal masuk, Jam masuk, Tambahan (diisi dengan tambahan yang ingin dititipkan misalnya, helm atau jas hujan) dan keterangan (sebagai keterangan kendaraan sedang parkir).

b. Menu Pencarian

Menu pencarian ini merupakan menu yang digunakan untuk mencari no polisi yang ingin keluar dari tempat penitipan.

c. Menu Tampilan

Menu tampilan ini merupakan menu yang digunakan oleh operator untuk melihat data penitipan, dimana pada menu ini terdapat data-data no polisi yang sedang melakukan penitipan.

d. Menu Informasi
Menu informasi ini merupakan menu yang digunakan operator untuk memberikan informasi tentang sisa tempat penitipan yang kosong.

e. Menu Keluar

Menu keluar merupakan menu untuk operator keluar dari sistem.

4. Tampilan Halaman untuk Atasan Halaman atasan adalah halaman yang digunakan untuk atasan mengolah data. Halaman atasan akan muncul setelah memasukkan username, password dan tipe untuk masuk sebagai atasan dengan benar maka akan tampil halaman untuk atasan. Pada halaman atasan disediakan menumenu yang meliputi menu beranda, menu daftar, menu data operator, menu laporan dan menu keluar.

a. Menu Beranda

Menu beranda ini merupakan menu awal ketika atasan masuk ke dalam program yang berisi tentang informasi sisa tempat parkir.

b. Menu Daftar

Menu daftar ini merupakan menu yang digunakan atasan untuk mendaftarkan username dan password operator yang baru.

Jika ada operator baru maka atasan mendaftarkan operator tersebut untuk membuatkan 
username dan password untuk hak akses ke halaman operator.

c. Menu Data Operator

Menu data operator ini merupakan menu yang digunakan atasan untuk melihat data operator yang telah terdaftar.

d. Menu Laporan

Menu laporan ini merupakan menu yang digunakan atasan untuk melihat laporan data perbulannya.

e. Menu Keluar

Menu keluar ini merupakan menu untuk atasan keluar dari sistem.

\subsection{Proses Upload ke Web Hosting}

Proses ini melakukan upload ke web hosting. Web hosting merupakann suatu sistem di internet yang memungkinkan siapapun agar dapat menyediakan informasi. Program dapat diakses secara online, melalui alamat http://penitipan-

terminalpwt.net84.net/parkir/. Tampilan secara keseluruhan dari localhost (offline) ataupun online semuanya sama. Database dan file aplikasi ini tersimpan di area hosting.

\subsection{Pengujian Jaringan}

Pengujian jaringan dilakukan untuk mengetahui koneksi jaringan internet yang ada dengan melakukan ping ke alamat http://penitipan- terminalpwt.net84.net/parkir/ pada command prompt.

\section{KESIMPULAN}

Pembuatan sistem informasi penitipan ini menghasilkan 3 user leveling yaitu operator, atasan dan pengguna parkir. Tabel yang dihasilkan dalam membuat sistem informasi penitipan ini sebanyak 3 tabel.

Pembuatan sistem informasi penitipan motor bebasis web dengan menggunakan PHP dan MySQL ini dapat diakses di komputer atau laptop dimanapun atasan dan pengguna parkir berada asalkan ada jaringan internet, karena sistem informasi ini telah di hosting. Dengan dibuatnya sistem informasi ini membantu operator dalam mengelola administrasi pembayaran penitipan dan mendata kendaraan yang input dan output dari tempat penitipan, mempermudah atasan mengakses data parkir atau laporan tiap bulannya, serta dapat memberikan informasi tentang penitipan kepada pengguna parkir.

\section{DAFTAR PUSTAKA}

[1] Hariyanto, Bambang, Rekayasa Sistem Berorientasi Objek. Bandung : Informatika, 2004.

[2] Hariyanto, Bambang. Sistem Manajemen BASISDATA. Bandung: Informatika, 2004.

[3] Jogianto HM.Sistem Informasi, 1989 
[4] Kadir, Abdul. Membuat Aplikasi Web dengan PHP dan Database MySQL. Yogyakarta: Andi Offset, 2009.

[5] Kadir,A. (2009). Dasar Perancangan \& Implementasi. Yogyakarta:ANDI.

[6] Kurniawan, Rulianto. Php dan MySQL untuk Orang Awam.Yogyakarta: Maxikom, 2010.

[7] Nazir, M. Metode Penelitian. Jakarta: Ghalia Indonesia, 1988.

[8] Rizky,Soetam. Konsep Dasar Rekayasa Perangkat Lunak. Jakarta: PT.Prestasi Pustakarya Indonesia, 2011.

[9] Shalahuddin, Rosa A.S-M. Rekayasa Perangkat Lunak.Bandung:

Modula,2011.

[10] Siallagan, Sariadin. Pemrograman Java Dasar-dasar Pengenalan $\&$ Pemahaman.Yogyakarta: Andi Offset, 2009.
[11] Sugiyono, P. D. Metode Penelitian Kuantitatif, Kualitatif, dan $R \& D$. Bandung: Alfabeta, 2009.

[12] Sutarman. Membangun aplikasiweb dengan PHP dan MySQL. Yogyakarta: Graha Ilmu,2003.

[13] Syafrizal, Melwin. Pengantar Jaringan Komputer.Yogyakarta: CV. Andi Offset, 2005.

[14] Anonymous. Konsep Dasar Informasi. http://parno.staff.gundarma.ac.id/Downl oads/file/4393/SI 01 Konsep_Dasar_S I.pdf, diakses pada 18 April 2012.

[15] Anonymous. Konsep Dasar Perangkat Lunak.

(elib.unikom.ac.id,pdf), diakses pada 9 mei 2012.

[16] Anonymous. Pengenalan Dasar Website. kampung Media Group, 2009.ppt, diakses pada 8 Mei 2012.

[17] Woody, 1927 